\title{
Biomonitoring of Danish school children and mothers including biomarkers of PBDE and glyphosate
}

Knudsen, Lisbeth E.; Hansen, Pernille Winton; Mizrak, Seher; Hansen, Heidi K.; Mørck, Thit A.; Nielsen, Flemming; Siersma, Volkert; Mathiesen, Line

Published in:

Reviews on Environmental Health

DOI:

10.1515/reveh-2016-0067

Publication date:

2017

Document version

Publisher's PDF, also known as Version of record

Document license:

Unspecified

Citation for published version (APA):

Knudsen, L. E., Hansen, P. W., Mizrak, S., Hansen, H. K., Mørck, T. A., Nielsen, F., Siersma, V., \& Mathiesen, L. (2017). Biomonitoring of Danish school children and mothers including biomarkers of PBDE and glyphosate. Reviews on Environmental Health, 32(3), 279-290. https://doi.org/10.1515/reveh-2016-0067 


\section{Lisbeth E. Knudsen*, Pernille Winton Hansen, Seher Mizrak, Heidi K. Hansen, Thit A. Mørck, Flemming Nielsen, Volkert Siersma and Line Mathiesen \\ Biomonitoring of Danish school children and mothers including biomarkers of PBDE and glyphosate}

DOI 10.1515/reveh-2016-0067

Received December 14, 2016; accepted January 17, 2017; previously published online March 17, 2017

\begin{abstract}
Background: The Danish part of the large European Human biomonitoring pilot project Demonstration of a study to Coordinate and Perform Human biomonitoring on a European Scale (DEMOCOPHES) investigated the urine, hair and blood concentrations of 66 different environmental chemicals in a group of 145 Danish school children aged 6-11 years and their mothers from rural and urban areas in autumn 2011. Some - but not all - results were published; however, the concurrence of the chemicals has not been assessed.
\end{abstract}

Methods: The measured concentrations of polybrominated diphenyl ethers (PBDEs) and glyphosate is assessed to complete the investigation of all 66 chemicals in DEMOCOPHES. The concentrations of PBDEs were measured in plasma samples of 143 mothers and 116 children. Glyphosate was measured in a subsample of 27 urine samples. Previously assessed chemicals were polychlorinated biphenyls (PCBs), and polyfluoroalkyl substances (PFASs) analyzed in blood samples, mercury analyzed in hair, and phthalate metabolites, parabens, phenols, cadmium, paracetamol and cotinine analyzed in urine samples. Differences in concentrations between mothers and children were assessed, and the associations between the

*Corresponding author: Lisbeth E. Knudsen, University of Copenhagen, Department of Public Health, Section of Environmental Health, Øster Farimagsgade 5, Room 5.2.12 DK 1353 Copenhagen, Denmark, Tel: + 45 35327653, E-mail: liek@sund.ku.dk Pernille Winton Hansen, Seher Mizrak, Heidi K. Hansen, Thit A. Mørck and Line Mathiesen: University of Copenhagen, Department of Public Health, Section of Environmental Health, Denmark

Flemming Nielsen: Department of Environmental Medicine, Institute of Public Health, University of Southern Denmark, 5000 Odense C, Denmark

Volkert Siersma: The Research Unit for General Practice and Section of General Practice, Department of Public Health, University of Copenhagen, Copenhagen, Denmark concentrations of the different environmental chemicals. investigated by correlation analysis.

Results: PBDE47 was found in relatively high levels compared with previous Danish results in both mothers and children, with a significantly higher level in the children compared to their mothers. Glyphosate in concentrations around $1 \mathrm{ng} / \mathrm{mL}$ was detected in all 27 samples. The analyzed environmental exposures seem to follow a pattern where chemicals within the same classes are strongly correlated and where children and mothers are exposed to the same chemicals.

Conclusion: The correlations between the measured environmental chemicals indicate that a specific exposure pattern may exist, where people who are highly exposed to one class of environmental chemicals also may be highly exposed to certain other classes. As some of the compounds were measured in higher levels in children compared to mothers, increased focus also on the exposure in young children is recommended. For more detailed investigation of specific exposure sources more studies with increased power and detailed questionnaires should be developed.

Keywords: children; DEMOCOPHES; exposure patterns; glyphosate; PBDE.

\section{Introduction}

A large variety of chemicals are added to consumer products with the purpose to ease and simplify various daily activities such as cooking, protection and cleaning of clothes and fabric as well as prevention of fires in electronics and furniture. Many of these chemicals are potentially harmful to humans if absorbed. Unfortunately, in many cases these chemicals do not stay in the product of intention, but gradually leach from the product, thereby exposing the consumers. New chemicals are continuously produced and some old chemicals such as persistent organic pollutants (POPs) are not rapidly degraded and can stay in the environment even long after their 
production and use in consumer products have been banned. Moreover, these chemicals may accumulate in the food chain which leads to increased human exposure. Human absorption of these chemicals can occur through oral ingestion, inhalation and dermal absorption.

An important tool in the investigation of chemical exposure in humans is human biomonitoring (HBM) where the concentration of a chemical, its metabolites or an early biomarker of effect is measured in a suitable sample of either the general population or people exposed to high levels of the chemical; either due to an accident, occupational exposure or similar. Particularly, HBM is useful in the assessment of time- or location-specific exposure-trends, and in identifying and investigating exposure in vulnerable groups (1).

A HBM framework was established by the Consortium to Perform Human biomonitoring on European Scale (COPHES), and a pilot study Demonstration of a study to Coordinate and Perform Human biomonitoring on a European Scale (DEMOCOPHES) was set up to test the feasibility of a harmonized HBM framework in Europe with the possibilities to compare exposure levels across borders and support environmental, health and chemical policies. In total 17 countries participated and sampling was performed from September 2011 to February 2012 (2). DEMOCOPHES gathered information on children aged 6-11 years and their mothers through questionnaires on lifestyle and diet, and hair and urine samples. Results from the full European study have been published by Den Hond et al. (2) and in a special edition of Environmental Research (3).

The Ministries of Health, Environment and Food Safety in Denmark requested and financed an expansion of the study by adding blood sampling of the participants to the Danish part of DEMOCOPHES. These blood samples were analyzed for content of several POPs, micronuclei and dioxin-like activity. The study of Danish urine samples was also expanded and analyzed for more than the standard DEMOCOPHES set of analyses.

Adverse effects associated with exposure to individual chemicals have been studied widely. However, the population is exposed to a mixture of many chemicals simultaneously and the health effects might therefore be a result of the total exposure to multiple chemicals. The health effects of mixtures of chemicals may not be the sum of the individual effects, which has been shown in animal studies $(4,5)$.

In the present study, we assess the mixed exposure to a set of chemicals of many different origins and include both non-persistent and persistent chemicals; both from the standard DEMOCOPHES analyses and the additionally obtained measurements. The persistent chemicals are measured in the blood and reflect exposure through months or years and are affected by bioaccumulation of the chemicals. These include biomarkers of polychlorinated biphenyls (PCBs), hexachlorobenzene (HCB), beta-hexachlorocyclohexane ( $\beta-\mathrm{HCH})$, dichlorodiphenyltrichloro-ethane (DDT), polyfluoroalkyl substances (PFASs) and polybrominated diphenyl ethers (PBDEs) which are all classified as (POPs). The non-persistent biomarkers were measured in the urine and reflect an exposure within the last $24 \mathrm{~h}$ due to their short half-lives (6). These include phthalate metabolites, parabens, phenols and the analgesic paracetamol in the full study population and the pesticide glyphosate in a subgroup. In Denmark, and six other countries the study was expanded by including bisphenol A (BPA) measurements in the urine (7). The individual exposures to many of these chemicals have been reported previously (8-14), but not the exposures to PBDEs - used as flame retardants - and glyphosate -a widely used herbicide.

PBDEs are synthetically produced compounds used as additives to retard fire and flames in a variety of commercial and household products such as furniture and electronics. Structurally PBDEs are similar to PCBs hence the nomenclature is based in the system developed for the PCBs. They are classified as POPs, that are highly bioaccumulative and biomagnify in fat tissues in fish and mammals including humans. Humans are primarily exposed through inhalation of dust, dermal absorption and intake of fish, poultry, meat and dairy products. PBDEs are toxic and studies in animals and epidemiological or HBM studies in humans have shown neurotoxic, endocrine disrupting and carcinogenic effects (15-18).

A subset of the Danish urine samples was also analyzed for glyphosate content. Glyphosate is the most widely used herbicide in the world, and has been in use since 1974 (19). In 1996, the first genetically engineered crops resistant to glyphosate were planted for commercial use in the USA, and the use of glyphosate-products has since risen markedly (20). The available studies of presence of glyphosate in human urine suggest that exposure differs between countries, and that even consumers who buy predominantly organic products are exposed. The general public is mostly exposed to glyphosate through diet or use of glyphosate products in private gardens.

In the present paper, we summarize the exposure to the previous reported biomarkers (8-14), and report data on exposure to PBDE and glyphosate. Furthermore, we assess the correlation between the exposures to the persistent environmental chemicals. 


\section{Materials and methods}

\section{Recruitment}

The recruitment of participants and collection of samples followed the COPHES/DEMOCOPHES developed protocol (21). In Denmark, children aged 6-11 years and their mothers were recruited via local schools in the selected areas representing rural (Viby Sjælland) and urban (Gentofte) communities. The rural and urban areas were selected according to population density, where $<150$ inhabitants $/ \mathrm{km}^{2}$ was defined as rural on the basis of DEMOCOPHES criteria. The parents of the children were contacted by email via school intranet and were encouraged to sign up and book an appointment through a project homepage. The following inclusion criteria were used: The child must be living primarily with the mother ( $>16$ days a month), and they must have been living in the same place for a minimum of 5 years, have sufficient Danish language knowledge and have normal kidney functions and must not suffer from metabolic disturbances. The goal of DEMOCOPHES was to reach 120 mother-child pairs in each country and with 75 pairs from urban area and 70 from rural area; the Danish part recruited 145 motherchild pairs in total. The children were equally distributed in gender, age and urban/rural location. All participants received detailed written information and gave consent before participating. Sampling was conducted in the urban and the rural area from September to December 2011 to minimize seasonal variation. The study was approved by the regional Ethics Committee in 2011 with supplementary approval of analyses of organophosphates including glyphosate (H-3-2011-075, H-1-2014-004). The data registry and biobank was approved by the Data Protection Agency (2011-41-6607).

\section{Sampling and biomarker analysis}

Urine spot samples were collected in $750 \mathrm{~mL}$ polyethylene containers, which were delivered to the home of the participants prior to the appointment for sample collection. When arriving at the laboratory, the containers were split into smaller tubes and stored at $-20^{\circ}$ or $-80^{\circ}$ until analysis. The analysis of 15 different phthalate metabolites, seven parabens and nine phenols were performed at the department of Growth and Reproduction at the University Hospital of Copenhagen $(12,22)$. The measurement of cotinine and creatinine were performed at the Department of Environmental Medicine at the University of Southern Denmark. The measurement of cadmium was performed at the Instituto de Salud Carlos III (ISCIII) in Madrid, Spain. The analysis is described in detail in (23). Analysis of paracetamol was performed at the Institute for Prevention and Occupational Medicine of the German Social Accident Insurance, at the Ruhr University in Bochum, Germany. The analysis is described in $(24,25)$. Supplementary analysis of concentration of glyphosate was performed in a subsample of 27 persons selected from rural and urban locations and analyzed by Laboratory Biocheck Leipzig, Germany by the Abraxis Glyphosate Plate Kit (ELISA) according to manufacturer's protocol (26).

The collection of blood samples was a supplement in the Danish part of DEMOCOPHES. Decline to venipuncture was respected. Blood sampling was performed by trained biomedical technicians with experience in blood sampling from children. For the analysis of POPs $20 \mathrm{~mL}$ blood was drawn in EDTA $\mathrm{K} 3$ plasma tubes and centrifuged for $10 \mathrm{~min}$ at $2000 \mathrm{~g}$. Plasma was transferred to $5 \mathrm{~mL}$ PP cryo tubes and stored in cooling box $\left(4^{\circ} \mathrm{C}\right)$ until arriving at the laboratory where it was stored at $-20{ }^{\circ} \mathrm{C}$ until further analysis. The plasma was analyzed for PCBs and dioxin-like activity (8), PFASs (9) and PBDEs at the University of Southern Denmark, which was also the DEMOCOPHES certified laboratory for mercury, cotinine and creatinine.

\section{PBDE analysis}

The analysis included the following compounds: BDE-28 (2,4,4'-Tribromodiphenyl ether), BDE-47 (2,2',4,4'-tetrabromodiphenyl ether), BDE-99 (2,2',4,4',5-pentabromodiphenyl ether), BDE-100 (2,2',4,4'6-pen-

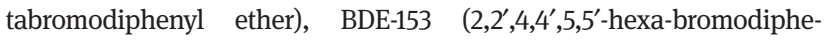

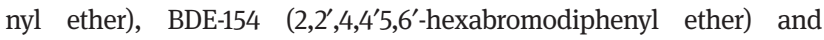
BDE-183 $\left(2,2^{\prime}, 3,4,4^{\prime}, 5^{\prime}, 6\right.$-heptabromodiphenyl ether) as well as the mass-labeled counterparts for BDE-47 (2,2',4,4'-Tetrabromo[13C12] diphenyl ether; BDE-99 (2,2',4,4',5-Pentabromo[13C12]diphenyl ether), BDE-100 (2,2',4,4'6-Pentabromo[13C12]diphenyl ether) and PBDE-153 $\left(2,2^{\prime}, 4,4^{\prime}, 5,5^{\prime}\right.$-Hexabromo[13C12]diphenyl ether); the latter used as internal standard for hexabromodiphenyl and heptabromodiphenyl ethers, were purchased from Wellington Laboratorie Inc., Guelph, ON, Canada. The quantitation of the PBDEs was performed on a Trace GC Ultra gas chromatographic system installed with a temperature programmable injector and a TSQ Quantum XLS tandem mass spectrometer operated in electronic ionization mode (Thermo Scientific, San Jose, CA, USA). The analytical separation was performed on a Rxi-5HT $15 \mathrm{~m} \times 0.25 \mathrm{~mm}$ ID $\times 0.1 \mu \mathrm{m}$ capillary column (Restek, Bellefonte, PA). Preparation of the samples by solid-phase extraction of the plasma samples was performed with two steps as described by (27). Due to PBDEs lipophilic characteristics, they were normalized to the total lipid content of the plasma sample and were reported as $\mathrm{ng} / \mathrm{g}$ lipid. The total lipid content was calculated from the cholesterol and triglyceride content determined on Konelab 20 Clinical Chemistry Analyzer (Thermo Scientific, Vantaa, Finland). The precision of the method was $<8.3 \%$, the repeatability was $<3 \%$ and the reproducibility ranged from 4.5 to $11.5 \%$. The LOD ranged from 0.2 to 2.5 ng/mL External quality control samples from (NIST (SRM 1958 Standard Reference Material 1958 (Organic Contaminants in Fortified Human Serum))) and in-house spiked horse serum samples as well as human plasma samples was included in each series of samples analyzed. The non-fortified horse serum was purchased from Sigma-Aldrich, Munich, Germany. The accuracy of the QC samples ranged from 86 to $106 \%$.

\section{Questionnaire}

The basic questionnaire and the urine-sampling related questionnaire developed by DEMOCOPHES were translated into Danish. The Danish questionnaire was expanded with questions regarding exposure relevant behavior, such as living conditions in relation to traffic exposure, use of personal care products and diet. These additions were made to obtain a more detailed assessment of the exposure sources. Average biomarker results of Danish participants and the total DEMOCOPHES study were sent to the Danish participants after end analysis and individual results were provided only if participants wished to know their individual results.

\section{Statistics}

Analysis of demographic, lifestyle, dietary and traffic-related characteristics of mothers and children were reported as numbers, 
percentages or mean with range separately for urban and rural residence. For those environmental chemicals that had more than 50\% values over limit of detection (LOD), the concentrations are reported as mean with range. Differences in these concentrations between mothers and their children were assessed by paired samples t-tests. Differences in concentrations of PBDEs between urban and rural residence were tested in ordinary independent sample t-tests. As the concentrations of PBDEs had a skewed distribution and had an increasing variance with higher measurements, these were ln transformed for the t-tests. The correlations between the concentrations of the different environmental chemicals were assessed, separately for mothers and children, by Spearman's rho $(\rho)$. Values for the environmental chemicals measured below LOD were set to $1 / 2$ LOD in all statistical analyses. The urinary chemicals were corrected for creatinine, however, correction for creatinine did not change the results of the statistical analysis (results not shown).

Statistical analyses were performed in IBM SPSS statistics version 20 and the R Environment for statistical computing. The statistical significance level was set to $\alpha=0.05$.

\section{Results}

The characteristics of the Danish study population are shown in Table 1. The study population consisted of 145 mother-child pairs with 70 pairs from rural area and 75 pairs from urban area. The children were equally distributed in gender and age. Blood samples were obtained from 143 mothers and 123 children.

\section{PBDEs}

The plasma samples from 143 mothers and 116 children were analyzed for PBDEs. BDE-28, BDE-47, BDE-99, BDE-100 and BDE-153 were detected in all the samples from both mothers and children, as shown in Table 2 . BDE-47 was found at relatively high levels (mean of $2.68 \mathrm{ng} / \mathrm{g}$ lipid) in 143 mothers, compared to previous Danish results with a mean of $0.86 \mathrm{ng} / \mathrm{g}$ lipid in 51 pregnant mothers (16). A significantly higher level in the 116 children (mean of $3.85 \mathrm{ng} / \mathrm{g}$ lipid), compared to mothers, was found (mean of $2.68 \mathrm{ng} / \mathrm{g}$ lipid). BDE-154 was detected in $36 \%$ of the mothers and $40 \%$ of the children, while BDE-183 was only detected in 5\% of the mothers and 2\% of the children.

\section{Glyphosate}

Urine samples from 13 mothers and 14 children were analyzed for glyphosate, and all samples contained detectable

Table 1: Characteristic of the participants in the Danish part of DEMOCOPHES.

\begin{tabular}{|c|c|c|c|c|c|c|}
\hline & \multicolumn{3}{|r|}{ Children } & \multicolumn{3}{|r|}{ Mothers } \\
\hline & Urban & Rural & All & Urban & Rural & All \\
\hline $\mathrm{n}$ & 75 & 70 & 145 & 75 & 70 & 145 \\
\hline Age, mean (range) & $8.5(6-11)$ & $8.5(6-11)$ & $8.5(6-11)$ & $42(31-52)$ & $40(31-50)$ & $41(31-52)$ \\
\hline Sex, $\mathrm{n}$ & $(35 \hat{\jmath}, 40 \uparrow)$ & $(35 \hat{\circ}, 35$ 웅 & $(70 \hat{\sigma}, 75+)$ & - & - & - \\
\hline $\mathrm{BMI}$, mean $\pm \mathrm{SD}$ & $16 \pm 1.2$ & $17 \pm 2.3$ & $16 \pm 2.3$ & $22 \pm 2.7$ & $25 \pm 5.7$ & $23 \pm 4.6$ \\
\hline Blood samples, $n$ & 61 & 62 & 123 & 73 & 70 & 143 \\
\hline Personal identity number provided, $n$ & 57 & 49 & 106 & 61 & 50 & 111 \\
\hline Request for personal data, $\mathrm{n}$ & - & - & - & 61 & 50 & 111 \\
\hline Woodstove in house, $n$ & 50 & 57 & 54 & 50 & 57 & 54 \\
\hline Smokers, n & - & - & - & 6 & 12 & 18 \\
\hline \multicolumn{7}{|l|}{ Dietary variables } \\
\hline Fish consumption several times a week & $36 \%$ & $39 \%$ & $39 \%$ & $57 \%$ & $30 \%$ & $44 \%$ \\
\hline Saltwater fish consumption, weekly & $48 \%$ & $39 \%$ & $43 \%$ & $48 \%$ & $46 \%$ & $47 \%$ \\
\hline Rice consumption, often & $43 \%$ & $31 \%$ & $37 \%$ & $69 \%$ & $71 \%$ & $70 \%$ \\
\hline Milk consumption, daily & $76 \%$ & $83 \%$ & $79 \%$ & $75 \%$ & $70 \%$ & $72 \%$ \\
\hline Cereal consumption, daily & $67 \%$ & $61 \%$ & $64 \%$ & $49 \%$ & $54 \%$ & $52 \%$ \\
\hline Meat consumption, daily & $67 \%$ & $71 \%$ & $69 \%$ & $48 \%$ & $60 \%$ & $54 \%$ \\
\hline Fast-food consumption, at least monthly & $43 \%$ & $59 \%$ & $58 \%$ & $51 \%$ & $59 \%$ & $55 \%$ \\
\hline Cheese consumption, at least monthly & $59 \%$ & $63 \%$ & $61 \%$ & $89 \%$ & $89 \%$ & $89 \%$ \\
\hline \multicolumn{7}{|l|}{ Traffic related variables } \\
\hline Window by bedroom door & $9 \%$ & $11 \%$ & $10 \%$ & $7 \%$ & $12 \%$ & $10 \%$ \\
\hline Polluted road within $50 \mathrm{~m}$ of home & $17 \%$ & $33 \%$ & $26 \%$ & $17 \%$ & $33 \%$ & $26 \%$ \\
\hline Location of work in high exposure area & - & - & - & $49 \%$ & $56 \%$ & $52 \%$ \\
\hline Total traffic - high exposure & $19 \%$ & $36 \%$ & $28 \%$ & $11 \%$ & $25 \%$ & $19 \%$ \\
\hline
\end{tabular}

BMI, body mass index. 


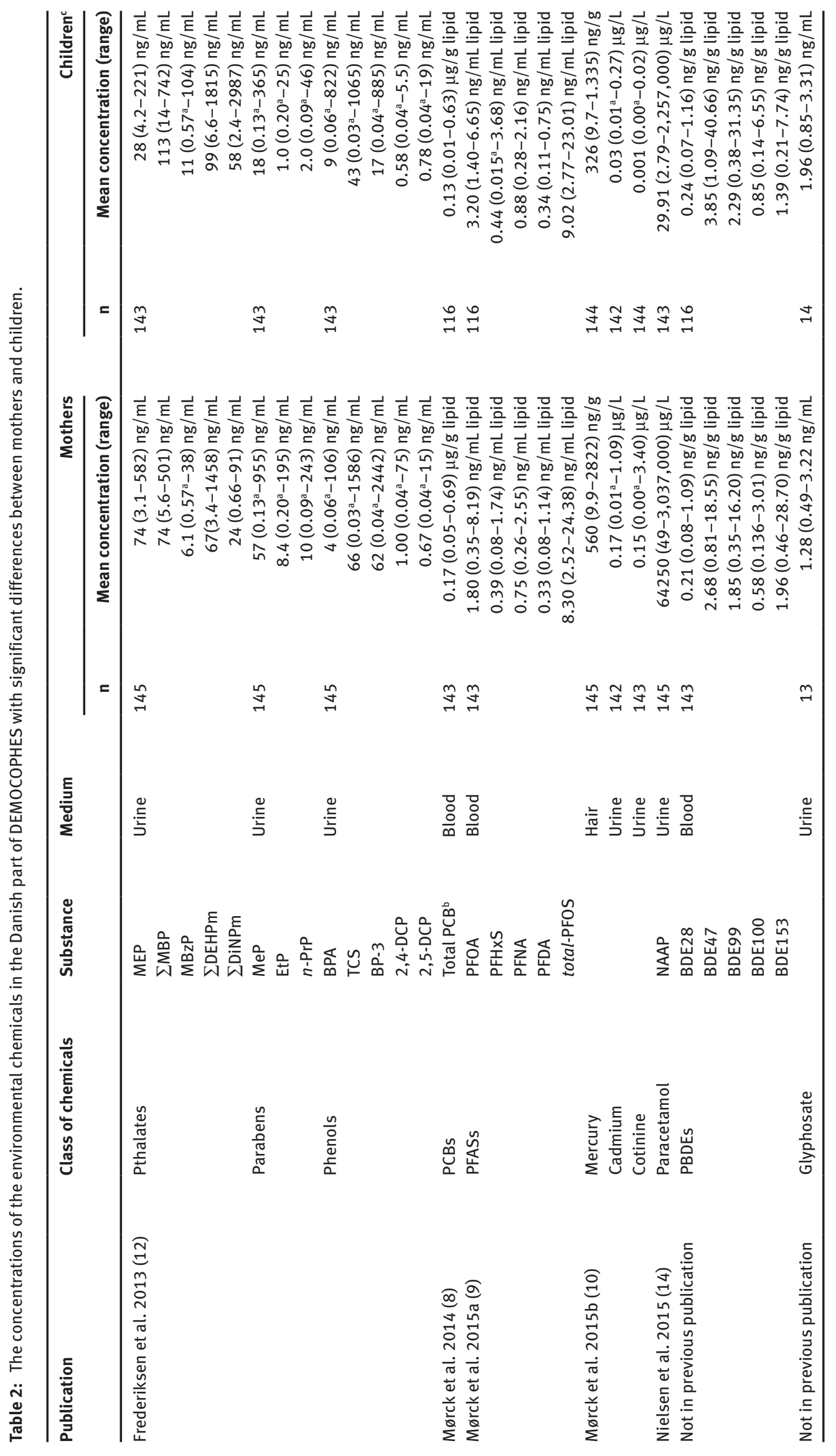




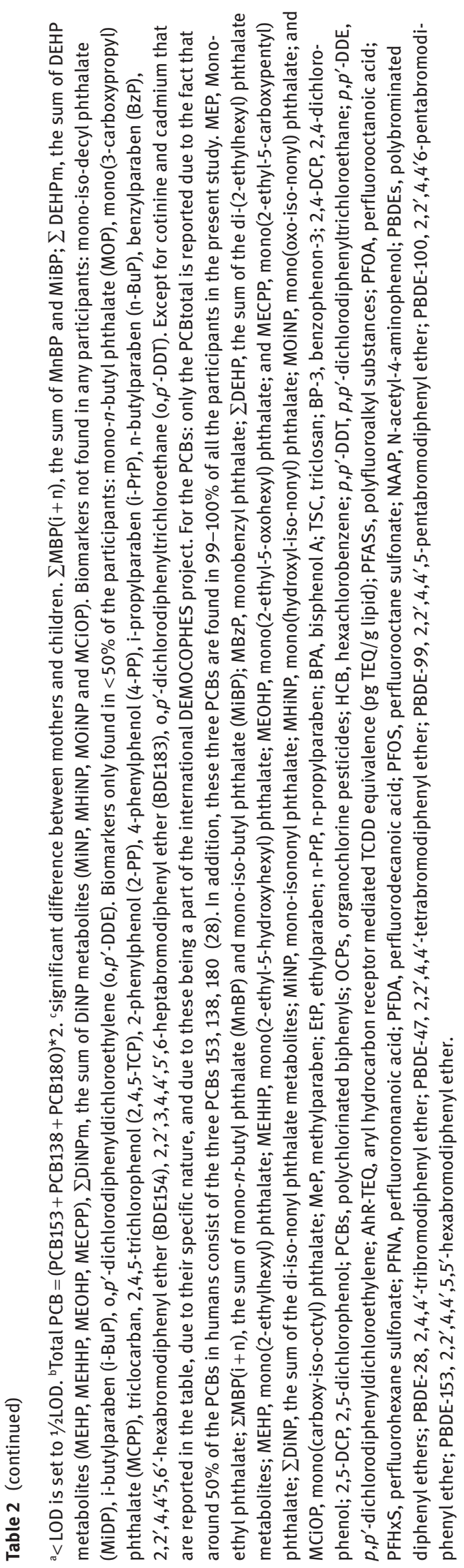

levels of glyphosate (See Table 2). There was no discernable difference between urban and rural residences.

\section{All biomarkers}

All of the 66 environmental chemicals were analyzed in the available samples, with blood samples available for only 116 of 145 children due to refusal of blood sampling. 23 chemicals were found in $100 \%$ of the mothers, while 22 chemicals were found in $100 \%$ of the children, with significant overlap of the chemicals found in both groups. Forty-eight of the biomarkers measured were detected in over $50 \%$ of the mothers, while 42 were detected in over $50 \%$ of the children. In Table 2, we have summarized a selection of biomarkers.

\section{Mother-child differences}

Table 2 shows the concentrations in mothers and children for a selected number of chemicals and classes of chemicals with significant differences between mothers and children. Children had higher concentrations of phthalates except Mono-ethyl phthalate (MEP) as also seen in DEMOCOPHES (2). Parabens and phenols were measured in higher concentrations in mothers compared to children, except BPA, which was also measured in higher concentration in children compared to mothers in the six DEMOCOPHES countries (7). Urine biomarkers of cadmium, cotinine, and paracetamol were significantly higher in mothers, while glyphosate was significantly higher in children. Serum concentrations of total PCBs and BDE-153 were higher in mothers compared to children while all Perfluorooctane sulfonate (PFOS) and BDE 28, 47, 99 and 100 were higher in children. The mother-child correlations were assessed for all biomarkers, and significant correlations were found for PCB 28 and 156, $\beta$-hexachlorocyclohexane ( $\beta$-HCH), $p, p^{\prime}$-dichlorodiphenyldichloroethylene $\left(p, p^{\prime}\right.$-DDE) and aryl hydrocarbon receptor mediated TCDD equivalence (pg TEQ/g lipid) (AhR-TEQ), all measured PFASs, mercury in hair, cotinine in urine as well as MN frequency and the PBDEs 28, 47, 100, and 153. All of the measured non-persistent substances correlations between mothers and children were found as previously reported.

Analysis of differences between living area and levels of the PBDEs showed significant higher levels of BDE-99, BDE-100 and BDE-154 in mothers from rural area and significant higher levels of BDE-28 in mothers from urban area. For children, the only significant differences were found in levels of BDE-99 and BDE-153, where BDE-99 was 


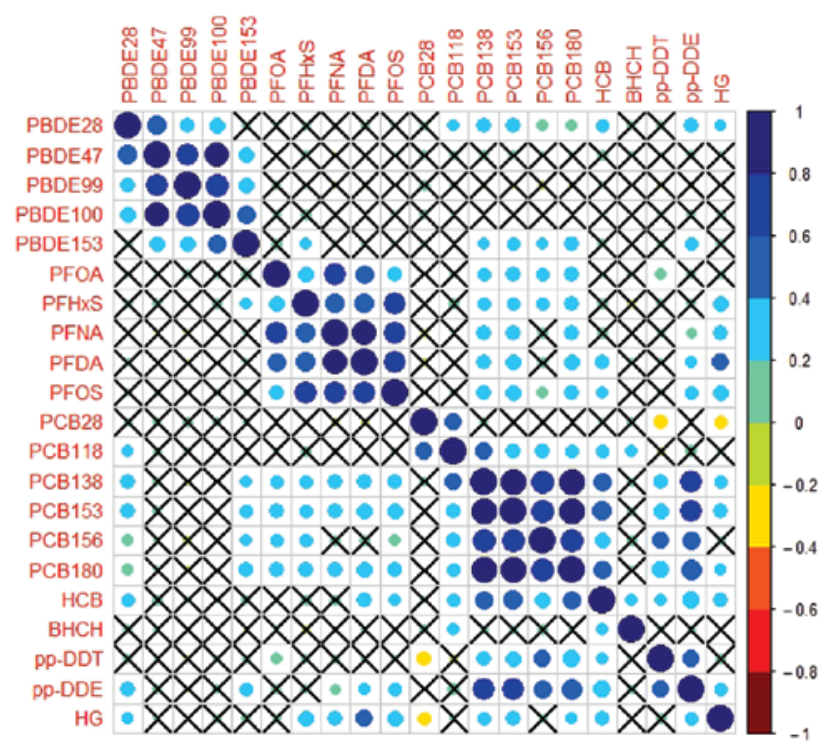

Figure 1: Correlation matrix for the POPs and mercury in children in the Danish part of DEMOCOPHES.

The figure shows the correlations between the measured POPs and mercury in children $(n=116)$. The color and size indicates the strength of the correlation. The color scale is shown on the right. A cross symbolizes that there is no significant correlation. Significance level was set to 0.05 .

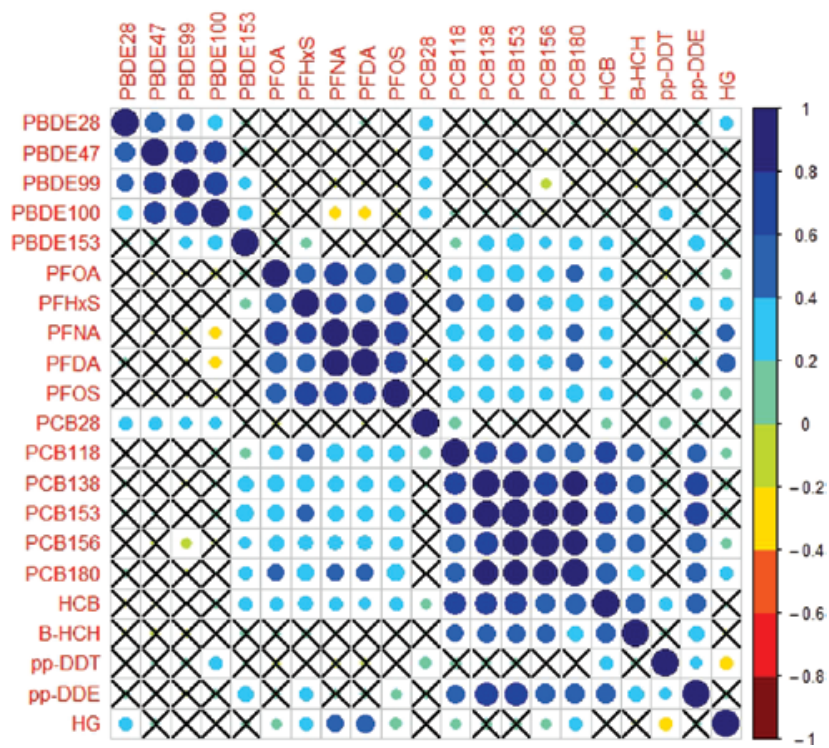

Figure 2: Correlation matrix for the POPs and mercury in mothers in the Danish part of DEMOCOPHES.

The figure shows the correlations between the measured POPs and mercury in mothers $(n=143)$. The color and size indicates the strength of the correlation. The color scale is shown on the right. A cross symbolizes that there is no significant correlation. Significance level was set to 0.05 . higher in rural area, and BDE-153 was higher in urban area (results not shown).

\section{Correlation between environmental chemicals}

Significant correlations were found between nearly all chemicals within the same class. Figures 1 and 2 shows, for mothers and children, respectively, the correlations within the same class and in the different groups of POPs and mercury.

For the non-persistent urinary biomarkers, moderate but statistically significant correlations were found between several of the chemicals from each class of phthalates, parabens and phenols, especially in children where MEP were significantly correlated with BPA, triclosan, benzophenone-3 and 2,4-dichlorophenol [2,4DCP $(\rho: 0.19-0.40, \mathrm{p}<0.05)]$ and BPA was correlated with the phthalates MBzP, diethylhexyl phthalate (DEHP) and Di-iso-butyl phthalate [DiNP $(\rho: 0.17-0.27, \mathrm{p}<0.05)$ ]. In mothers, 2,5-DCP was correlated with the parabens $(\rho: 0.2-0.22, \mathrm{p}<0.05)(12)$.

Finally, the correlations between the urinary, blood and hair biomarkers were tested, and no consistent pattern of correlations between whole classes of chemicals was observed, but there were a few sporadic significant correlations (29).

\section{Discussion}

\section{PBDES}

For four out of five of the PBDEs, significantly higher levels were detected in children, in all of the children and adult samples. The higher levels detected in children may be partly due to the relatively small body size and blood volume of children relative to their ingestion, leaving them with smaller body storage for the compounds. Furthermore, the exposure burden may be larger in children compared to adults, because of immature metabolic pathways in children (30). The higher concentrations found in children may also be due to different sources of exposure in mothers and children, or that children are exposed to a higher degree than their mothers. Although the children in this study are not toddlers, it is likely that they get into more contact with floor dust than their mothers, causing 
higher exposure to the PBDEs. A study of exposure in Danish newborns and mothers showed clear correlation between maternal PBDE serum levels and dust PBDE (31). That study also found a positive correlation between number of electronic devices in the homes and PBDE in the mothers (unpublished).

Higher levels for several PBDEs in mothers as well as children in rural areas, may be due to house construction in the 1960s using carpets and other constructions with PBDEs, consistent with higher rural PCB28 levels from sealing materials used in these houses (13). A subsample of mothers and 3-year-old children from the Norwegian Mother Child Cohort 1999-2005 showed lower concentrations in Norway compared to Danish levels (32). The Danish levels in children were lower than concentrations reported in National Health and Nutrition Examination Survey (NHANES) 2003-2004 (33), and in the studies of 9-12-year-old children in California in 200-2002 (34). In addition, levels in adult Danish females were lower compared to the adult pregnant women in NHANES 2003-2004 (35).

\section{Glyphosate}

Glyphosate concentrations in the Danish sample of 13 mothers and 14 children are in line with the German study ("Urinale 2015"), which detected glyphosate residues in $99.6 \%$ of the spot urine samples from 2011 participants, using the same analytical method (AbraxisELISA-test method, with LOD $0.0751 \mu \mathrm{g} / \mathrm{L}$ ). The mean value for all samples was $1.08 \mathrm{ng} / \mathrm{mL}$, with a maximum value of $4.2 \mathrm{ng} / \mathrm{mL}$. The youngest participants in the German study - with participants ranging from 0 to 9 years and 10 to 19 years - had the highest concentrations of glyphosate in the urine $(36,37)$. Further unpublished studies of 24 adult Danes, using the same analytical method confirmed the level of $1 \mathrm{ng} / \mathrm{mL}$. Conrad et al. (38) analyzed archived samples from 2001-2015 provided by 20 to 29-year-old individuals living in Greifswald, a city in north-eastern Germany. Out of the 399 analyzed urine samples, 127 (31.8\%) contained glyphosate concentrations at or above the limit of quantification (LOQ) of $0.1 \mu \mathrm{g} / \mathrm{L}$. Male donors had the highest levels and an increase over time was observed.

In 2013, 182 human spot urine samples from 18 European countries were tested for glyphosate and its metabolite aminomethylphosphonic acid (AMPA) (GC-MS/MS method with LOQ $0.15 \mu \mathrm{g} / \mathrm{L}$ ). On average, $44 \%$ of the samples were above the limit of quantification (LOQ) $(0.15 \mu \mathrm{g} / \mathrm{L})$, but the frequency of detection across countries varied from $10 \%$ to $90 \%$. The highest glyphosate concentration was $1.82 \mu \mathrm{g} / \mathrm{L}$ from a Polish sample (the highest AMPA $2.6 \mu \mathrm{g} / \mathrm{L}$, sample from Croatia) (39).

In a study of 26 Portuguese volunteers from an urban area conducted by the 'Portuguese No GMO Coalition', glyphosate was detected in all samples in a range from $12.5-32.5 \mathrm{ng} / \mathrm{mL}$, with an average amount of $26.2 \mathrm{ng} / \mathrm{mL}$, which is much higher than levels in German and Danish studies (LC-MS/MS method with LOQ $0.5 \mathrm{ng} / \mathrm{mL}$ ) (40).

In Denmark, glyphosate residues have been found in, e.g. barley, wheat grain, wheat flour, oat grain, cornflakes, dried lentils, and dried chickpeas, either from Danish or foreign origin $(41,42)$, all below the current maximum residue level (MRL). Assuming 20-30\% uptake from food and no metabolism, these values are substantially below the acceptable daily intake (ADI) and acute reference dose (ARfD) set by the European Food Safety Authority (EFSA) (43) in 2015 to $0.5 \mathrm{mg} / \mathrm{kg}$ body weight/day, with the acceptable operator exposure level (AOEL) at $0.1 \mathrm{mg} /$ $\mathrm{kg}$ body weight/day (EFSA, 2015). However, the possible carcinogenic potential of glyphosate is discussed by the International Agency on Research of Cancer (IARC), which has classified glyphosate as a probable carcinogen (group 2A) (44), and the EFSA, which states that there is no carcinogenic risk from oral exposure to glyphosate residues in food (ref). Information about human absorption, metabolism and excretion rate (half-life) is very scarce, with only one human study reporting apparent elimination half-life around $3.1 \mathrm{~h}$ (45) versus half-lives of $33 \mathrm{~h}$ reported for rodents (44). If the half-life is as short as $3.1 \mathrm{~h}$, the sampling time becomes critical in interpretation of exposures.

\section{All biomarkers in the study}

The specific sources of exposures were only found in few compounds, that have been discussed in previous publications. Mercury concentrations in hair have been associated with fish consumption as described previously in Mørck et al. (10), which has also been confirmed in DEMOCOPHES $(2,23)$ and in other studies (46-49).

The source of PCB 28 was investigated further in the Danish participants, and concentrations of PCB 28 were significantly higher in both mothers and children living in houses built in the period (1950-1977), when PCBs were used in construction and sealants in houses to a higher degree than houses built earlier (13).

Six DEMOCOPHES countries found a significant association between BPA and consumption of canned food in mothers (7), which was also found in Spanish pregnant 
women (50). The use of personal care products by mothers was associated with higher concentrations of phthalates and parabens (12). All these findings support the hypothesis of lifestyle- and dietary-related exposures, even to non-persistent chemicals.

The was significant positive correlation between concentrations of some persistent chemicals and metals to the age of the mothers in the present study. The increase in concentration of persistent chemicals correlated to increasing age of adults is consistent with previous studies and expectable, as accumulation of persistent chemicals in humans increase over time (51-57).

Significant correlations were found for all POPs within the same class, as reported also in the literature. (55, 58-60), Simultaneous exposure to chemicals within the same class indicates that the compounds are either used together in the same products, or that similar products are often used by the same consumers. The presence of persistent chemicals is a result of many years of exposure, accumulation, and metabolism of the chemicals. Nearly all compounds measured in the present study can be categorized as endocrine disruptors, some of which have been suspected to affect the reproductive system in males, as well as play an important role in the decline of semen quality and increase in testicular cancer in Denmark (61-63). Effects on reproduction in females have also been reported for compounds measured in the present study (64-67). Furthermore, neurological and immunological effects have been associated to chemical exposure $(28,58$, 68,69 ).

Bonefeld-Jørgensen et al. (70) emphasizes the need for both epidemiological and in vitro/ex vivo studies to investigate the potential impact of the effect of multiple POPs on human health. The most efficient way to prevent these health effects is to reduce exposure by increasing regulation with regards to limiting the chemical content in consumer products, and issuing public recommendations on diet and other exposure-related habits.

The strength of analyzing many different biomarkers is that it provides a more detailed exposure map, as well as the possibility of elucidating exposure patterns between the different classes of chemicals. However, it can also be an advantage to limit the number of congeners in each chemical class, or merge some of the congeners, to represent the overall chemical for both practical and economic reasons.

The mother-child correlations found in this study may be due to the influence mothers have over their children at this age, and the choice their mothers make regarding main household products used. In a German study, this exposure pattern was found for phthalates and BPA (71).
The questionnaire is based on the DEMOCOPHES questionnaire used in all participating countries. As ingestion is the primary source of many chemicals, a more detailed food frequency questionnaire may facilitate the identification of specific sources.

The cross-sectional design of this study limits the reproducibility of the individual measurements of nonpersistent chemicals, as there may be day-to-day variation dependent on the exposure within the last $24 \mathrm{~h}$, due to short half-lives (6). The average data is however very useful in estimating the general exposure levels.

\section{Conclusion}

In conclusion, the exposure to chemicals in the Danish participants of the present study is ubiquitous.

The correlations between the measured environmental chemicals indicate that there may be a specific exposure pattern, where people who are highly exposed to one class of environmental chemicals could also experience high exposure to certain other classes. As some of the compounds were measured at higher levels in children compared to mothers, increased focus on the exposure in young children is recommended. For a more detailed investigation of specific exposure sources, more studies with increased power and detailed questionnaires should be developed.

With the abundant simultaneous exposure to many chemicals, there is a risk of adverse health effects, with specific emphasis on the exposure of children, since they are sensitive to exogenous stimuli. Furthermore, many of the mothers are of a fertile age, placing increased importance on limitation of exposure during pregnancies.

\section{Author Statement}

Research funding: This study was made possible through the participation of 145 Danish school children and mothers in the European project DEMOCOPHES cofunded by the LIFE+ program of EU (GD environment LIFE09 ENV/BE/000410) and the Danish Environmental Agency, the Danish Veterinary and Food Administration and the Danish Health and Medicines Authority. COPHES (consortium to perform human biomonitoring on a European scale) provided protocols, etc. for the HBM study, COPHES (COnsortium to Perform Human Biomonitoring on a European Scale) was funded by the Seventh EU Framework Program 2007-2011 under grant agreement no. 244237. Conflict of interest: Authors state no conflict of interest. Informed consent: All participants received 
detailed written information and gave consent before participating. Ethical approval: The study was approved by the regional Ethics Committee in 2011 with supplementary approval of analyses of organophosphates including glyphosate (H-3-2011-075, H-1-2014-004). The data registry and biobank was approved by the Data Protection Agency (2011-41-6607).

\section{References}

1. Angerer J, Ewers U, Wilhelm M. Human biomonitoring: state of the art. Int J Hyg Environ Health 2007;210:201-28.

2. Den Hond E, Govarts E, Willems H, Smolders R, Casteleyn L, et al. First steps toward harmonized human biomonitoring in Europe: demonstration project to perform human biomonitoring on a European scale. Environ Health Perspect 2015;123(3):255-63.

3. Aerts D, Casteleyn L, editors. Harmonized human biomonitoring on a European scale: experiences in seventeen countries. Environ Res 2015;141:1-132.

4. Axelstad, M, Christiansen S, Boberg J, Scholze M, Jacobsen PR, et al. Mixtures of endocrine-disrupting contaminants induce adverse developmental effects in preweaning rats. Reproduction 2014;147:489-501.

5. Christiansen S, Scholze M, Dalgaard M, Vinggaard AM, Axelstad $M$, et al. Synergistic disruption of external male sex organ development by a mixture of four antiandrogens. Environ Health Perspect 2009;117:1839-46.

6. LaKind JS, Aylward L, Brunk C, DiZio S, Dourson M, et al. Guidelines for the communication of Biomonitoring Equivalents: report from the Biomonitoring Equivalents Expert Workshop. Regul Toxicol Pharmacol 2008;51:16-26.

7. Covaci A, den Hond ED, Geens T, Govarts E, Koppen G, et al. Urinary BPA measurements in children and mothers from six European member states: Overall results and determinants of exposure. Environ Res 2015;141:77-85.

8. Mørck TA, Erdmann SE, Long M, Mathiesen L, Nielsen F, et al. $P C B$ concentrations and dioxin-like activity in blood samples from Danish school children and their mothers living in urban and rural areas. Basic Clin Pharmacol Toxicol 2014;115:334-44.

9. Mørck TA, Nielsen F, Nielsen JKS, Siersma VD, Grandjean P, et al. PFAS concentrations in plasma samples from Danish school children and their mothers. Chemosphere 2015a;129:203-9.

10. Mørck TA, Nielsen F, Nielsen JKS, Jensen JF, Hansen PW, et al. The Danish contribution to the European DEMOCOPHES project: a description of cadmium, cotinine and mercury levels in Danish mother-child pairs and the perspectives of supplementary sampling and measurements. Environ Res 2015b;141:96-105.

11. Mørck TA, Andersen HR, Knudsen LE. Organophosphate metabolites in urine samples from Danish children and women - Measured in the Danish DEMOCOPHES population. Danish Ministry of the Environment/Environmental Protection Agency, 2016.

12. Frederiksen H, Nielsen JKS, Mørck TA, Hansen PW, Jensen JF, et al. Urinary excretion of phthalate metabolites, phenols and parabens in rural and urban Danish mother-child pairs. Int J Hyg Environ Health 2013;216:772-83.
13. Egsmose EL, Bräuner EV, Frederiksen M, Mørck TA, Siersma VD, et al. Associations between plasma concentrations of PCB 28 and possible indoor exposure sources in Danish school children and mothers. Environ Int 2016;87:13-19.

14. Nielsen JKS, Modick H, Mørck TA, Jensen JF, Nielsen F, et al. $\mathrm{N}$-acetyl-4-aminophenol (paracetamol) in urine samples of 6-11-year-old Danish school children and their mothers Int J Hyg Environ Health 2015;218(1):28-33.

15. Frederiksen M, Vorkamp K, Thomsen M, Knudsen LE. Human internal and external exposure to PBDEs - a review of levels and sources. Int J Hyg Environ Health 2009;212:109-34.

16. Frederiksen M, Thomsen C, Frøshaug M, Vorkamp K, Thomsen M. Polybrominated diphenyl ethers in paired samples of maternal and umbilical cord blood plasma and associations with house dust in a Danish cohort. Int J Hyg Environ Health 2010;213:233-42.

17. Kim YR, Harden FA, Toms LM, Norman RE. Health consequences of exposure to brominated flame retardants: a systematic review. Chemosphere 2014;106:1-19.

18. Fromme H, Becher G, Hilger B, Völkel W. Brominated flame retardants - Exposure and risk assessment for the general population. Int J Hyg Environ Health 2016;219:1-23.

19. Duke SO, Powles SB. Glyphosate: a once-in-a-century herbicide. Pest Management Science 2008;64:319-25.

20. Myers JP, Antoniou MN, Blumberg B, Carroll L, Colborn T, et al. Concerns over use of glyphosate-based herbicides and risks associated with exposures: a consensus statement. Environ Health 2016;15:1-13.

21. Becker K, Seiwert M, Casteleyn L, Joas R, Joas A, et al. A systematic approach for designing a HBM pilot study for Europe. Int J Hyg Environ Health 2014;217:312-22.

22. Frederiksen H, Aksglaede L, Sorensen K, Nielsen O, Main KM, et al. Bisphenol $A$ and other phenols in urine from Danish children and adolescents analyzed by isotope diluted Turbo Flow-LC- MS/MS. Int J Hyg Environ Health 2013;216:710-20.

23. Castano A, Cutanda F, Esteban M, Part P, Navarro C, et al. Fish consumption patterns and hair mercury levels in children and their mothers in 17 EU countries. Environ Res 2015;141:58-68.

24. Dierkes G, Weiss T, Modick H, Kafferlein HU, Bruning T, et al. NAcetyl-4-aminophenol (paracetamol), $\mathrm{N}$-acetyl-2-aminophenol and acetanilide in urine samples from the general population, individuals exposed to aniline and paracetamol users. Int J Hyg Environ Health 2014;217:592-99.

25. Modick H, Schutze A, Palmke C, Weiss T, Bruning T, et al. Rapid determination of $\mathrm{N}$-acetyl-4-aminophenol (paracetamol) in urine by tandem mass spectrometry coupled with on-line clean-up by two dimensional turbulent flow/reversed phase liquid chromatography. J Chromatogr 2013;925:33-9.

26. Abraxis. Glyphosate Plate Kit Part No. 500086. Warminster (PA); 2005.

27. Sjodin A, Jones RS, Lapeza CR, Focant JF, McGahee EE, et al. Semiautomated high-throughput extraction and cleanup method for the measurement of polybrominated diphenyl ethers, polybrominated biphenyls, and polychlorinated biphenyls in human serum. Anal Chem 2004;76:1921-7.

28. Grandjean P, Weihe P, Burse VW, Needham LL, Storr-Hansen E, et al. Neurobehavioral deficits associated with PCB in 7-year-old children prenatally exposed to seafood neurotoxicants. Neurotoxicol Teratol 2001;23:305-17 
29. Mørck TA, Loock KV, Poulsen MB, Siersma VD, Nielsen JK, et al. Micronucleus frequency in Danish schoolchildren and their mothers from the DEMOCOPHES population. Mutagenesis 2015;31(1):1-8.

30. Landrigan PJ, Goldman LR. Children's vulnerability to toxic chemicals: a challenge and opportunity to strengthen health and environmental policy. Health Aff (Millwood) 2011;30:842-50.

31. Vorkamp K, Thomsen M, Frederiksen M, Pedersen M, Knudsen LE. Polybrominated diphenyl ethers (PBDEs) in the indoor environment and associations with prenatal exposure. Environ Int 2011;37:1-10.

32. Caspersen IH, Kvalem HE, Haugen M, Brantsæter AL, Meltzer $\mathrm{HM}$, et al. Determinants of plasma PCB, brominated flame retardants, and organochlorine pesticides in pregnant women and 3 year old children in The Norwegian Mother and Child Cohort Study. Environ Res 2016;146:136-44.

33. Sjödin A, Schecter A, Jones R, Wong LY, Colacino JA, et al. Poly-

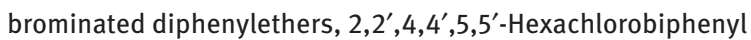
(PCB153) and p, $\mathrm{p}^{\prime}$-Dichlorodiphenyldichloroethylene ( $p, \mathrm{p}^{\prime}$-DDE) Concentrations in sera collected in 2009 from texas children. Environ Sci Technol 2014;48:8196-202.

34. Sagiv SK, Kogut K, Gaspar FW, Gunier RB, Harley KG, et al. Prenatal and childhood polybrominated diphenyl ether (PBDE) exposure and attention and executive function at 9-12 years of age. Neurotoxicol Teratol 2015;52:151-61.

35. Donauer S, Chen A, Xu Y, Calafat A, Sjödin A, et al. Prenatal exposure to polybrominated diphenyl ethers and polyfluoroalkyl chemicals and infant neurobehaviour. J Pediatr 2015;166:736-42.

36. Krüger M, Lindner A, Heimrath J. Nachweis von Glyphosat im Urin freiwilliger, selbstzahlender Studienteilnehmer - "Urinale 2015".

37. Krüger M, Lindner A, Heimrath J. Auswertung von 2011 Humanurinproben auf ihren Glyphosatgehalt. 2016.

38. Conrad A, Schröter-Kermani C, Hoppe W, Rüther M, Pieper S, et al. Glyphosate in German adults - Time trend (2001 to 2015) of human exposure to a widely used herbicide. Int J Hyg Environ Health 2017;220:8-16.

39. Hoppe HW. Determination of Glyphosate residues in human urine samples from 18 European countries https://www. foeeurope.org/sites/default/files/glyphosate_studyresults_ june12.pdf.

40. Portuguese No GMO Coalition, 2016. International press release 09-05-2016. http://www.stopogm.net/glifosato-herbicida-quecontamina-portugal.

41. Jensen BH, Andersen JH, Petersen A, Hilbert G, Grossmann A, et al. Pesticidrester i fødevarer 2013. Copenhagen, Denmark. [Danish Veterinary and Food Agency].

42. Jensen BH, Andersen JH, Grønhøj L, Hilbert G, Grossmann A, et al. Pesticidrester i fødevarer 2014. Copenhagen, Denmark. [Danish Veterinary and Food Agency].

43. EFSA (European Food Safety Authority), Conclusion on the peer review of the pesticide risk assessment of the active substance glyphosate. EFSA Journal 2015;13(11):4302, 107.

44. IARC. Glyphosate IARC Monographs Vol. 112 [Internet]. 2015. Available from: http://monographs.iarc.fr/ENG/Monographs/ vol112/mono112-02.pdf.

45. Roberts DM, Buckley NA, Mohamed F, Eddleston M, Goldstein DA, et al. A prospective observational study of the clinical toxicology of glyphosate-containing herbicides in adults with acute self-poisoning. Clin Toxicol 2010;48:129-36.
46. Jenssen MT, Brantsaeter AL, Haugen M, Meltzer HM, Larssen $T$, et al. Dietary mercury exposure in a population with a wide range of fish consumption - self-capture of fish and regional differences are important determinants of mercury in blood. Sci Total Environ 2012;439:220-9.

47. Passos CJ, Mergler D, Lemire M, Fillion M, Guimaraes JR. Fish consumption and bioindicators of inorganic mercury exposure. Sci Total Environ 2007;373:68-76.

48. Schaefer AM, Jensen EL, Bossart GD, Reif JS. Hair mercury concentrations and fish consumption patterns in Florida residents. Int J Environ Res Public Health 2014;11:6709-26.

49. Sherman LS, Blum JD, Franzblau A, Basu N. New insight into biomarkers of human mercury exposure using naturally occurring mercury stable isotopes. Environ Sci Technol 2013;47:3403-9.

50. Casas M, Valvi D, Luque N, Ballesteros-Gomez A, Carsin AE, et al. Dietary and sociodemographic determinants of bisphenol $A$ urine concentrations in pregnant women and children. Environ Int 2013;56:10-8.

51. Chien LC, Gao CS, Lin HH. Hair mercury concentration and fish consumption: risk and perceptions of risk among women of childbearing age. Environ Res 2010;110:123-9.

52. Dirinck E, Jorens PG, Covaci A, Geens T, Roosens L, et al. Obesity and persistent organic pollutants: possible obesogenic effect of organochlorine pesticides and polychlorinated biphenyls. Obesity 2011;19:709-14.

53. Fromme H, Midasch O, Twardella D, Angerer J, Boehmer S, et al. Occurrence of perfluorinated substances in an adult German population in southern Bavaria. Int Arch Occup Environ Health 2007;80:313-9.

54. Haug LS, Thomsen C, Becher G. Time trends and the influence of age and gender on serum concentrations of perfluorinated compounds in archived human samples. Environ Sci Technol 2009;43:2131-6.

55. Haug LS, Thomsen C, Brantsaeter AL, Kvalem HE, Haugen M, et al. Diet and particularly seafood are major sources of perfluorinated compounds in humans. Environ Int 2010;36:772-8.

56. Hue O, Marcotte J, Berrigan F, Simoneau M, Dore J, et al. Plasma concentration of organochlorine compounds is associated with age and not obesity. Chemosphere 2007;67:1463-67.

57. Kato K, Wong LY, Jia LT, Kuklenyik Z, Calafat AM. Trends in exposure to polyfluoroalkyl chemicals in the U.S. population: 1999-2008. Environmental Science \& Technology 2011;45:8037-45.

58. Gump BB, Wu Q, Dumas AK, Kannan K. Perfluorochemical (PFC) exposure in children: associations with impaired response inhibition. Environ Sci Technol 2011;45:8151-9.

59. Vagi SJ, Azziz-Baumgartner E, Sjodin A, Calafat AM, Dumesic D. Exploring the potential association between brominated diphenyl ethers, polychlorinated biphenyls, organochlorine pesticides, perfluorinated compounds, phthalates, and bisphenol a in polycystic ovary syndrome: a case-control study. BMC Endocr Disord 2014;14:86.

60. Vorkamp K, Nielsen F, Kyhl HB, Husby S, Nielsen LB, et al. Polybrominated diphenyl ethers and perfluoroalkyl substances in serum of pregnant women: levels, correlations, and potential health implications. Arch Environ Contam Toxicol 2014;67:9-20.

61. Juul A, Almstrup K, Andersson AM, Jensen TK, Jorgensen N, et al. Possible fetal determinants of male infertility. Nat Rev Endocrinol 2014;10:553-62. 
62. Vested A, Giwercman A, Bonde JP, Toft G. Persistent organic pollutants and male reproductive health. Asian J Androl 2014;16:71-80.

63. Wohlfahrt-Veje C, Main KM, Skakkebaek NE. Testicular dysgenesis syndrome: foetal origin of adult reproductive problems. Clin Endocrinol (Oxf) 2009;71:459-65.

64. Buck Louis GM, Sundaram R, Schisterman EF, Sweeney AM, Lynch CD, et al. Persistent environmental pollutants and couple fecundity: the LIFE study. Environ Health Perspect 2013; 121:231-6.

65. Chevrier C, Warembourg C, Gaudreau E, Monfort C, Le Blanc A, et al. Organochlorine pesticides, polychlorinated biphenyls, seafood consumption, and time-to-pregnancy. Epidemiology 2013;24:251-60.

66. Fei C, McLaughlin JK, Lipworth L, Olsen J. Maternal levels of perfluorinated chemicals and subfecundity. Hum Reprod 2009;24:1200-5.

67. Jensen TK, Andersen LB, Kyhl HB, Nielsen F, Christensen HT, et al. Association between perfluorinated compound expo- sure and miscarriage in Danish pregnant women. PLoS One 2015;10(4):e0123496.

68. Grandjean P, Andersen EW, Budtz-Jorgensen E, Nielsen F, Molbak K, et al. Serum vaccine antibody concentrations in children exposed to perfluorinated compounds. J Am Med Assoc 2012;307:391-7.

69. Kicinski M, Viaene MK, Den Hond E, Schoeters G, Covaci A, et al. Neurobehavioral function and low-level exposure to brominated flame retardants in adolescents: a cross-sectional study. Environ Health 2012;11:86.

70. Bonefeld-Jørgensen EC, Mandana G, Wielsøe M, BjerregaardOlesen C, Kjeldsen LS, et al. Biomonitoring and hormonedisrupting effect biomarkers of persistent organic pollutants in vitro and ex vivo. Basic Clin Pharmacol Toxicol 2014; 115:118-28.

71. Kasper-Sonnenberg M, Koch HM, Wittsiepe J, Wilhelm M. Levels of phthalate metabolites in urine among mother-child-pairs results from the Duisburg birth cohort study, Germany. Int J Hyg Environ Health 2012;215:373-82. 